\title{
DEATHS FOLLOWING DROWNING IN SRI LANKA - A RETROSPECTIVE STUDY -
}

\section{Paranitharan P, Perera WNS, Lakmal S, Priyanath DC, Senanayake TAAW \& Kumari MKJK}

DOI:

http://doi.org/10.4038/sljfmsl. v11i2.7857

Corresponding Author Paranitharan $\mathbf{P}$

Department of Forensic Medicine, Faculty of Medicine, University of Kelaniya, Sri Lanka

paran28@gmail.com

https://orcid.org/00000002-1913-6085

Key Words

Circumstances, contributory factors, deaths, drowning

Article history

Received: 02.09.2019

Received in revised form: 18.05.2020

Accepted: 11.06.2020

Available online: 21.12.2020

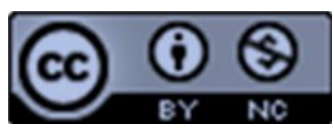

This article is licensed under the terms of the Creative Commons Attribution-Non Commercial 4.0 International License.

e-ISSN: $2465-6089$

\begin{abstract}
Introduction: Deaths following drowning are a common occurrence in Sri Lanka. Individuals drown in different circumstances like suicides, accidents and homicides. A study of this nature would be useful for prevention of such incidences and as a baseline for future studies.
\end{abstract}

Objectives: With regard to victims of drowning to determine; the demographic profile, circumstances, autopsy findings and contributory factors for drowning.

Methodology: Information was extracted from records of 59 drowning cases in the years 20082017. Data were analysed using the statistical package SPSS Version 22.

Results: Majority of deaths (37.3\%) were within the age of 11-30 years. Twenty-six-point five percent (26.5\%) of accidental deaths were within the age group 11-20 years. The circumstances were accident $(57.6 \%)$, suicide (22\%) and not known whether accident or suicide (20.3\%). The common places of accidental drowning were sea (20\%), Tank (20\%) and canal (18\%.) The well was the most common place for suicides (54\%). Majority of victims were unemployed (37\%) and labourers (25\%). Froth in the nostrils (54.2\%), Emphysematous expanded lungs $(63 \%)$, rib indentation on the lungs (61\%) froth in the airways $(61 \%)$ and pulmonary oedema (66\%) were observations which were suggestive of drowning.
Environmental factors (41\%) and alcohol consumption (20\%) are among the possible contributory factors.

Conclusion: Majority of the deaths are accidental. Environmental factors and alcohol consumption may play contributory roles. Awareness programmes targeting young adults will minimize accidental deaths.

\section{INTRODUCTION}

Drowning is the process of experiencing respiratory impairment from submersion/ immersion in liquid according to the WHO World Congress on Drowning. Death, morbidity and no morbidity following immersion are the common outcomes of drowning. ${ }^{1}$ Deaths following drowning number around 372,000 per year worldwide and is considered a serious and neglected public health issue. ${ }^{1}$ Drowning is one of the ten leading causes of death for people aged 1-24 years in every region of the world. ${ }^{1}$ The low- and middle-income countries contribute to more than $90 \%$ of unintentional drowning deaths. $^{2}$ Moreover, globally more than half of the drowning deaths involve victims who are less than 25 years. No significant efforts have been taken to prevent drowning in comparison to the preventative mechanisms adopted for noncommunicable diseases. Bodies found in water needs thorough forensic investigation to establish cause and manner of death. ${ }^{3}$ 
The Life Saving Association of Sri Lanka developed a report in collaboration with Life Saving Victoria and the World Health Organization, country office for Sri Lanka. (December 2014). According to the report Sri Lanka has one of the highest drowning rates internationally, ranking 12th highest in a comparison of 61 countries, and 10th highest when compared to 35 Low- and Middle-Income Countries (LMIC). On average, 855 people drown in Sri Lanka each year, a drowning rate of 4.4 deaths per 100,000 persons (from 2001, 2006 and in 2009). ${ }^{4}$ Further the report revealed North Western (6.3\%) and North Central (5.4\%) provinces had a higher drowning death rate than the national average (4.4 per $100,000)$. Even in some of the provinces adjoining the ocean (Eastern and Northern), the commonest location of drowning was reportedly lakes and wells. ${ }^{4,5}$ The ministry of disaster management had led a multidisciplinary team and was specifically interested in drowning prevention and water safety of Sri Lanka. ${ }^{6}$

The environmental factors such as rough sea, sudden rise of water levels, floods and water sources of unknown depths were some of the causes that contributed towards drowning in this study. The presence of alcohol in stomach contents may also have contributed in drowning deaths.

A study of this nature will highlight the significance of deaths related to drowning by mainly considering the demographic factors, circumstances and contributory factors. Maintaining a national data base, sensitizing authorities to the importance of preventive measures and encouraging future research on morbidity and deaths related to drowning are the expected outcomes of this study.

\section{OBJECTIVES}

With regard to victims of drowning to determine; the demographic profile, circumstances, autopsy findings and contributory factors for drowning.

\section{MATERIALS AND METHODS}

The 59 deaths, due to drowning which occurred in the period 2008-2017 confirmed as drowning by death investigation were included. Data were extracted from postmortem reports and analysed using the statistical package SPSS version 22. The drowning deaths involving unidentified individuals were excluded from the study. The majority were fresh bodies $(n=39)$ with the rest with various time intervals of decomposition.

\section{RESULTS}

Majority of the drowning deaths have occurred in the age group between $11-20$ years (18.6\%), $21-30$ years $(18.6 \%)$ and $31-40$ years $(16.9 \%)$. It was rarely seen in the extremes of age; $1.7 \%$ in the age group less than 10 years and $1.7 \%$ in those between $81-90$ years. The predominant gender was male (81.4\%).

While the commonest circumstance was accident $(57.6 \%)$ followed by suicide $(22 \%)$. In $20.3 \%$ of cases the circumstance was unascertainable. There were no homicides.

When considering the age distribution in accidental deaths the majority were between $11-20$ years. (26.5\%), followed by $(17.6 \%)$ between the ages of $21-30$ years, (17.6\%) between $31-40$ years and (17.6\%) between 5160 years. The $41-50$ years age group represented $5.9 \%$. The extremes of age groups such as less than 10 years were $2.9 \%$ and $61-70$ years $11.8 \%$.

Table 1: Occupation

\begin{tabular}{ll}
\hline Occupation & Number (\%) \\
\hline Unknown & $13(38)$ \\
Unemployed & $11(32)$ \\
Labourer & $07(21)$ \\
Army Soldier & $01(3)$ \\
Businessman & $01(3)$ \\
Clerk & $01(3)$ \\
Total & $34(100)$ \\
\hline
\end{tabular}


The table 1 shows the drowned individuals were mostly unemployed (32\%) or labourers (21\%). The documentation regarding (38.2\%) of individuals was not available in the autopsy reports.

It was found to be difficult to extract the information from the reports regarding the capabilities to swim of most of the individuals in accidental drowning. Details regarding the diseased ability to swim were not documented in half of the drowned individuals (50\%). The other important observation was $38.2 \%$ of the individuals who drowned can swim. The rest could not swim.

Table 2: Place of drowning in accidental deaths

\begin{tabular}{ll}
\hline Place of drowning & Number (\%) \\
\hline Sea & $7(20)$ \\
Tank & $7(20)$ \\
Canal & $6(18)$ \\
River & $5(15)$ \\
Well & $3(9)$ \\
Flooded area & $2(6)$ \\
Pit & $1(3)$ \\
Lagoon & $1(3)$ \\
Stream & $1(3)$ \\
Not known & $1(3)$ \\
Total & $34(100)$ \\
\hline
\end{tabular}

The sea (20\%), tank (20\%), canal (17\%) and river (15\%) were the common locations for accidental drowning (Table 2).

Majority (52.9\%) of accidental drownings have occurred between 12- $6.00 \mathrm{pm}$. Twenty nine percent had occurred from 6 am to 12 noon while only $5.9 \%$ had occurred from 6.pm to 6 am. In $11.8 \%$ of cases the time was not known.
Table 3: Place of drowning in suicidal deaths

\begin{tabular}{cl}
\hline Place of Drowning & Number (\%) \\
\hline Well & $7(54)$ \\
Canal & $3(23)$ \\
Sea & $2(15)$ \\
River & $1(8)$ \\
\hline Total & $13(100)$ \\
\hline
\end{tabular}

Majority of suicidal drowning has taken place in wells and canals (table 3 ). Majority of bodies recovered were fresh $(n=39,66.1 \%)$.

The signs supportive of drowning during the external examination were white foamy froth or pinkish froth in the nostrils ( $n=32,54.2 \%)$ and cadaveric spasm $(n=1,1.7 \%)$. No signs were present in 26 (44.1\%) deaths.

Table 4: Features supportive of drowning during the internal examination (more than 01 sign may be present)

\begin{tabular}{|c|c|}
\hline Feature & Number (\%) \\
\hline Pulmonary oedema & $39(66)$ \\
\hline $\begin{array}{l}\text { Emphysematous, expanded } \\
\text { lungs }\end{array}$ & $37(63)$ \\
\hline Rib indentation on the lungs & $36(61)$ \\
\hline Froth presents in the airways & $36(61)$ \\
\hline Congestion & $24(41)$ \\
\hline $\begin{array}{l}\text { Foreign particles beyond } \\
\text { secondary bronchi }\end{array}$ & $18(30)$ \\
\hline $\begin{array}{l}\text { Lungs covering the anterior } \\
\text { border of the heart }\end{array}$ & $15(25)$ \\
\hline Asphyxial features & $07(12)$ \\
\hline No signs were present & $05(9)$ \\
\hline $\begin{array}{l}\text { Inference: } \\
\text { emphysematous lungs, rib in } \\
\text { froth in airways are importa } \\
\text { drowning. }\end{array}$ & $\begin{array}{c}\text { oedema, } \\
\text { tations and }\end{array}$ \\
\hline
\end{tabular}


Table 5: Contributory factors for accidental drowning

\begin{tabular}{ll}
\hline \multicolumn{1}{c}{ Contributory factor } & Number (\%) \\
\hline $\begin{array}{l}\text { Environmental factors } \\
\text { (rough sea, sudden rise of } \\
\text { water level, floods etc.) }\end{array}$ & $14(41)$ \\
No reason identified & $8(23)$ \\
Alcohol consumption & $7(21)$ \\
Inability to swim & $2(6)$ \\
Natural disease & $1(3)$ \\
Neurological impairment & $1(3)$ \\
Psychiatric illness & $1(3)$ \\
\hline Total & $34(100)$ \\
\hline
\end{tabular}

Environmental factors and alcohol consumption were the most common possible contributory factors. In a significant proportion of persons, no reasons were identified.

\section{DISCUSSION}

Sri Lanka which is an island has distinguished hydraulic civilization, famous for irrigation tanks, canals and rivers. People especially of small villages have access to natural water pools or irrigation tanks which they use for their daily needs including entertainment. Most people have their own well which may be protected or unprotected. In some of the villages people cross water canals on wooden blocks without adequate protection or use a wooden stage (Paruwa) for transport along waterways. Due to heavy rain in the central hill country water levels may suddenly rise in the lower regions without warning. Even though sea beaches have warning signs with graded risk, irrigation tanks do not have the same. Sometimes without knowing the actual depths children and adults drown being poor swimmers especially in irrigation tanks and sea. Life guards are available only in a few beaches. Once someone starts to drown, the outcome is often fatal. Unlike other injuries, survival is determined almost exclusively at the scene of the incident, and depends on two highly variable factors: how quickly the person is removed from the water, and how swiftly proper resuscitation is performed. ${ }^{1}$

The data based on surveillance of drowning deaths is minimal in Sri Lanka. The overwhelming majority of drownings happen in low and middle income countries where people have close daily contact with water for work, transport and agriculture. ${ }^{1}$ The data collection in many low and middle income countries is limited, hampering the planning, implementation and monitoring of drowning prevention measures. ${ }^{1}$ This study illustrates similar observations made by the WHO in Sri Lanka and other countries which exhibit similar environment. The affected individuals are mostly males and mostly come from the age group of adolescents and young adults as seen in other similar studies. ${ }^{7,8}$ They tend to prefer bathing, swimming and travel in water such as sea, lake, river and other water sources.

The peer pressure may be so intense that groups of individuals seek to enter water for pleasure and fun related activities. Unforeseen natural calamities cause death due to drowning even in certain cases where the drowned individual can swim. ${ }^{1,4}$ Sri Lanka is a culturally sensitive country with a male preponderance for water related activities. Female children are restricted and often supervised by elders. They are not left alone frequently to indulge in swimming or bathing in open water sources. In schools with swimming pools there is no gender bias but in other instances there may be. Boys and young males are not supervised stringently and they are free to go on trips with their friends and swim at any places. Lack of awareness sometimes makes them vulnerable to swim in dangerous locations.

Majority of cases are accidental drowning and most of them belong to the 11-20 years age group. Most of the accidental deaths have taken place in the sea, irrigation tanks or canals. These are the preferred places sought after by the youth for recreational swimming and pleasure. 
In contrary to this a drowning related study done in an enlarged European union revealed the susceptibility of elders rather than the young adults. ${ }^{9}$ Another study on drowning deaths in river was stressing the importance to identify the research gaps and rectify them timely. ${ }^{10}$ Suicidal drowning was seen in $22 \%$ of cases. Most of the individuals have chosen the well for this purpose. The easy access to this water source at the time of an emotional disturbance could be a plausible explanation. The prevention of suicides should be addressed as whole in the country and jumping into water is only one way of committing suicides in comparison to the other methods like hanging and ingestion of poison. ${ }^{11}$ Identifying the trends in accidental and suicidal drowning deaths will help to take preventive measures in future.

If a careful analysis of the social background is given it was obvious that most of the individuals who got accidentally drowned were either labourers or unemployed with the available data. It is postulated that they may be using these water ways for their daily needs. They may be not in a position to frequent places which are safe and provided with life guards. This group of socially unnoticed individuals needs special attention. It is not quite obvious whether lack of literacy has any preponderance towards accidental drowning. However, if an individual is wealthy, he may avoid unsafe water sources.

Lunch and evening hours are considered to be more preferable for a water related activity resulting in more accidental deaths. Similar fatal drowning incidents were mostly observed between 12.00 and $2 \mathrm{pm}$ in South Africa. ${ }^{12}$

The information regarding the ability to swim of the individuals were not available in most occasions. Moreover $38 \%$ were able to swim in accidental deaths. The lack of information in $50 \%$ of cases emphasizes the poor recording regarding the background of the drowned victims and was a limitation in relation to future prevention measures. The other striking finding is the capacity of $38 \%$ of individuals who can swim. Sometimes the ability to swim may encourage risky behaviour and thus may result in drowning. In a country with adequate literacy, children of school going years must be trained in swimming as a life skill to avoid accidental deaths due to drowning. Sri Lanka surrounded in all fronts by sea with the interior containing lakes, water reservoirs and manmade wells makes it more prone to an individual to die from drowning.

Fresh body was found in most occasions. The immediate recovery of bodies following drowning deaths is important since decomposition changes will interfere with the interpretation of autopsy findings. Since the drowning is a diagnosis of exclusion of other causes, the recovery of the body at the earliest opportunity will minimize hidden homicides.

$1 / 3^{\text {rd }}$ of bodies were decomposing at the time of autopsy indicating delayed recovery of the body from water ways. Deaths taking place in sea and large water reservoirs often make difficulties for the rescuers to find the missing persons and thus results in long delays and decomposition.

The signs including the characteristic froth were not observed during the external examination in $44.1 \%$ of cases. This could be due to the presence of decomposition or dry drowning. Nearly $60 \%$ of victims had froth in the air way, rib indentation, expanded lungs and pulmonary oedema as the most observed internal features indicating wet drowning among the victims. This study revealed that the autopsy findings both external and internal contributed to arrive at the cause of death and all the bodies may not show the features to support drowning. ${ }^{13}$ The diatoms test was used in the past to diagnose drowning but it is not done in all forensic centers now. A study done in Sri Lanka revealed the prevalence of different types of diatoms found in autopsy samples. ${ }^{14}$ This study sample did not involve travelers or tourists from other countries. 
However, the overall safety measures to prevent drowning deaths will certainly benefit the tourists as well. A study published in the journal of travel medicine highlights some of the prevention measures. ${ }^{15}$ Further there are limited research articles available regarding the epidemiology of drowning containing quantitative data in low- and middle-income countries. ${ }^{16}$ Hence, making space for more research work towards drowning.

The high altitude of sea waves, sudden rise of water level, rough sea and floods are some of the important and dangerous environmental factors that may have contributed in accidental deaths in this study. Deaths have occurred even with individuals who know swimming. The lack of environmental signs indicating dangerous areas may prone entry into harmful water sources. Alcohol consumption was suspected in seven individuals following accidental deaths, with the available history and presence of alcohol in the stomach. When analyzing the background of an accidental drowning death, the in-depth analysis of contributory factors is important to prevent future deaths. Three were miscellaneous reasons like psychiatric illness; neurological disability etc. identified in this study but the exact contribution is difficult to prove. A study done in Sweden explains the role of alcohol consumption in drowning deaths involving children. The risk factors included: coming from a single parent-headed family, alcohol use by older victims and a lack of ability to swim. ${ }^{17}$ Another study done in United Kingdom involving children emphasizes the role of adult supervision in preventing drowning related deaths. ${ }^{18}$

It is important to strengthen the role of a national governing entity to finalize the national action plan and establish a national governing entity for drowning prevention and water safety. ${ }^{6}$ "The National Advisory Committee will develop a proposal on risk profile, customize beach/pool operational guidelines, improve swim for safety curriculum, identify and promote safe bathing and swimming zones, and develop a surveillance system to be framed into the National Action Plan of Sri Lanka". The role of the national governing entity would be to implement the national action plan and monitor progress, assigning steering and technical committees to decentralize the solutions ${ }^{6}$.

The data collection in Sri Lanka is limited being a serious debacle in planning, implementing and monitoring of drowning prevention measures. Further the near drowning cases also may go unnoticed which often results in life long impairment of functions and heavily dependent on healthcare facilities. ${ }^{1}$ It is imperative to carry out an island wide research analyzing all the drowning deaths with possible contributory factors. As a way forward to minimize drowning deaths preventive measures should be initiated starting from the schools. The citizens of all ages must be educated of the dangers of swimming in unknown and dangerous water resources. There are individuals who use water sources to commit suicide by drowning. A Sri Lankan study found $3 \%$ of the suicides due to drowning. ${ }^{19}$ In the global scenario drowning is among the 10 leading causes of death of children and young adults in every region of the world and males with a higher probability in comparison to females. ${ }^{1}$

A simple study of this nature will narrow down the important demographic factors, circumstances and other contributory factors of drowning and will strengthen further research on drowning.

The policy frame work is active and well designed to prevent drowning deaths in Sri Lanka. A suitable data base covering the whole island related to drowning deaths would be an added advantage for further researches. 


\section{CONCLUSIONS}

Majority of the deaths were accidental. The common places of drowning in accidental deaths were the sea and irrigation tank.

\section{RECOMMENDATIONS}

1. A national data surveillance on drowning deaths by an established authority

2. Establish lifesaving associations at town and village levels

3. Include mandatory swimming lessons in school curriculum

4. Provide national funding for research targeting morbidity and mortality due to drowning

5. Establish a government mechanism to collect data on drowning related incidents, water safety and training to prevent drowning related deaths

6. Develop an action plan for water safety and prevention of drowning deaths.

7. A prospective study regarding drowning deaths involving all provinces should be initiated.

8. Governments and other non-governmental organizations must prioritize prevention of drowning deaths and integrate with other public health issues.

\section{LIMITATIONS OF THE STUDY}

The sample size was small and reflects the autopsy experience of the authors. As this is a retrospective study, the recording of autopsy findings may show minor subjective variations but may not influence the cause of death. The decomposed bodies in comparison to fresh bodies may pose difficulties in autopsy findings but have not compromised the cause of death.

However, the trends observed were similar to other parts of the world and corresponds to the previous studies done in Sri Lanka. Further it is presumed the geographical variations regarding water sources are minimal in low altitude areas.

\section{ETHICAL ISSUES}

The data was generated as a collective one and individual identity is not available. The study adhered to the ethical guideline of the medicolegal institution and the health facility. This was a retrospective study.

\section{CONFLICTS OF INTEREST}

There are no conflicts of interest.

\section{AUTHOR CONTRIBUTIONS}

PP: Conception and design of the work, identifying the key data to be analyzed, interpretation of data, initial drafting and addressing amendments from reviewers and editors, and final approval; WNSP: Conception and design of the work, identifying the key data to be analyzed, interpretation of data, amendments to the initial draft by first author, and final approval; SL: Conception of the work, identifying the key data to be analyzed, interpretation of data, and final approval; DCP: Conception of the work, identifying the key data to be analyzed, interpretation of data, and final approval; TAAWS: Conception of the work, analysis of data and tabulation, and final approval; MKJKK: Conception of the work, analysis of data and tabulation, and final approval. 


\section{REFERENCES}

1. World Health Organization. Global report on drowning: preventing a leading killer. [online] Available from: https://www.who.int/ publications/i/item/global-report-on-drowningpreventing-a-leading-killer.

2. World Health Organization. Drowning. [online] Available from: https://www.who.int/newsroom/fact-sheets/detail/drowning

3. Armstrong EJ, Erskine $\mathrm{KL}$. Investigation of drowning deaths: a practical review. Academic forensic pathology. 2018 Mar;8(1):8-43. doi:10.23907/2018.002.

4. Scribd. Drowning Prevention Report, Sri Lanka 2014. [online] Available from: https://www.scribd.com/document/251418871 /Drowning-Prevention-Report-Sri-Lanka-2014

5. Matthews B, Birch R, Jayawardena $M$, et al. 824 A cross country analysis of drowning in Sri Lanka: 2001 to 2006 and 2009. Injury Prevention. 2016;22:A295. doi: 10.1136/injuryprev-2016-042156.824.

6. Ministry of disaster management. Towards A National Plan: Drowning Prevention and Water Safety, 3-7, July, 2017.

7. Perera S, Jayatilleke YD, Jayasiri J. An Anthropological analysis on the present face of ancient hydraulic civilization in Sri Lanka: with special reference to the socio economic and cultural study on Kapirikgama Cascade of North Central Province, In: Proceedings of the 10th International Conference on Sri Lanka Studies, University of Kelaniya, pp 28.

8. Phad LG, Dhawane SG. Epidemiological profile of drowning deaths: a cross sectional study. Egypt journal of forensic sciences. 2018 Dec 1;8(1):26. doi:10.1186/s41935-018-0056-8.

9. Patetta MJ, Biddinger PW. Characteristics of drowning deaths in North Carolina. Public health reports. 1988 Jul-Aug; 103(4): 406-411.

10. Peden $A E$, Franklin RC, Leggat PA. Fatal river drowning: the identification of research gaps through a systematic literature review. Injury prevention. 2016 Jun 1;22:202-209. doi:10.1136/injuryprev-2015-041750.
11. Knipe DW, Metcalfe C, Fernando R, et al. Suicide in Sri Lanka 1975-2012: age, period and cohort analysis of police and hospital data. BMC Public health. 2014 Dec 1;14(1):839. doi: 10.1186/1471-2458-14-839.

12. Saunders CJ, Adriaanse R, Simons A, van Niekerk A. Fatal drowning in the Western Cape, South Africa: a 7-year retrospective, epidemiological study. Injury Prevention. 2019 Dec 1;25(6);52934. doi: 10.1136/injuryprev-2018-042945.

13. Stephenson L, Van den Heuvel C, Byard RW. The persistent problem of drowning-A difficult diagnosis with inconclusive tests. Journal of forensic and legal medicine. 2019 Aug 1;66:7985. doi: 10.1016/j.jflm.2019.06.003.

14. Gunatilake PGL, Gooneratne I. Drowning associated diatoms in Sri Lanka. Sri Lanka journal of forensic medicine, science \& law. 2011 Jan 20;1(2).

15. Cortés LM, Hargarten SW, Hennes HM. Recommendations for water safety and drowning prevention for travelers. Journal of travel medicine. 2006 Jan 1;13(1):21-34. doi:10.1111/j.1708-8305.2006.00002.x.

16. Tyler MD, Richards DB, Reske-Nielson $C$, et al. The epidemiology of drowning in low- and middle-income countries; a systematic review. BMC public health. 2017 Dec;17(1):1-7. doi:10.1186/s12889-017-4239-2.

17. Schyllander J, Janson S, Nyberg C, Eriksson UB, Ekman DS. Case analyses of all children's drowning deaths occurring in Sweden 19982007. Scandinavian journal of public health. 2013 Mar;41(2):174-9. doi:10.1177/ 1403494812471156.

18. Kemp A, Sibert JR. Drowning and near drowning in children in the United Kingdom: lessons for prevention. British Medical Journal. 1992 May 2;304(6835):1143-1146.

doi: 10.1136/bmj.304.6835.1143.

19. Fernando $R$, Hewagama $M$, Priyangika WD, Range $S$, Karunaratne $S$. Study of suicides reported to the coroner, Colombo, Sri Lanka. Medicine, Science the Law. 2010 Jan;50(1):25-8. doi:10.1258/msl.2009.009012. 